\title{
MicroRNA Dysregulation Associated with Red Blood Cell Storage
}

\author{
Xiaojie Chen $^{a}$ Xuhong Xie ${ }^{a}$ Yanfen Xing $^{a} \quad$ Xiuhua Yang $^{a}$ Zhaohu Yuan ${ }^{a}$ Yaming Wei ${ }^{a, b}$ \\ a Department of Blood Transfusion, Guangzhou First People's Hospital, School of Medicine, South China University of Technology, \\ Guangzhou, Guangdong, China; \\ ${ }^{b}$ Guangdong Technology Engineering Center of Precision Blood Transfusion, Guangzhou, Guangdong, China; \\ ' Guangdong Key Laboratory of Clinical Molecular Medicine and Diagnostics, Guangzhou First People's Hospital, School of Medicine, \\ South China University of Technology , Guangzhou, Guangdong, China
}

\section{Keywords}

Stored RBCs · miRNA dysregulation · Storage lesion · Hemorheology

\section{Summary}

Introduction: Stored red blood cells (RBCs) undergo storage lesions involving morphological, physiological and biochemical changes. MicroRNAs (miRNAs) have important functions in cell apoptosis and life processes. Therefore, the aim of this study was to explore potential roles of miRNAs in the damage of stored RBCs. Methods: Blood samples were collected from 13 healthy male O-type donors, and leuko-reduced RBCs were divided into fresh RBC group and 20-day storage RBC group. Results: Eight predicted miRNAs with modified expressions with an intersection $\geq 3$ were found dysregulated in the 20-day storage RBC group and involved in apoptosis and senescence signaling pathway: miR-31-5p, miR-196a-5p, miR-203a, miR-654-3p and miR-769-3p were increased, while miR-96-5P, miR-150-5P and miR197-3p were decreased. Evidence associating miR-31-5p, miR-203a, miR-654 and miR-769 to RBCs or blood in general are not available. Conclusions: Dysregulated miRNAs might represent potential biomarkers to identify storage lesions, and their detection might help to evaluate the quality of stored RBCs.

(c) 2018 S. Karger GmbH, Freiburg

Xiaojie Chen and Xuhong Xie contributed equally to this work.

\section{Introduction}

Biochemical changes of stored red blood cells (RBCs) may occur during storage, even under approved conditions set by regulatory agencies. These alterations of stored RBCs, known as storage lesions, are primarily divided into three types: biochemical, morphological, and structural $[1,2]$. During storage, RBC alterations may result in their easy disruption during transfusion, which could be harmful to the transfusion recipient $[1,3-5]$. In addition, previous studies demonstrate that RBC alterations may be of crucial importance for the maintenance of normal circulation [6-11].

MicroRNAs (miRNAs) are known to regulate the expression of genes that are especially relevant in differentiation and apoptosis via mRNA degradation or translation inhibition. miRNAs have also been implicated in many human diseases, and the resulting altered cellular states can be used as biomarkers [12-14]. As cells differentiate into reticulocytes, the nuclei are extruded, and cytoplasmic RNAs (including mRNAs and miRNAs) and translation activities remain detectable [15]. Diverse and abundant miRNAs exist in mature erythrocytes, but their functions are still unknown [16]. miRNA expression in erythrocytes is different from that found in reticulocytes or leukocytes. Nucleated cells had substantially higher miRNA content on a per cell basis, but the hematopoietic cellular contribution to miRNA content of blood on a volume basis is highest in erythrocytes [17]. Therefore, these miRNAs likely play a significant role in posttranscriptional regulation in erythroid cells [16, $18,19]$. Profiling studies on RBCs have reported that the expression of several miRNAs can dramatically change during storage, and among them apoptosis-associated miRNAs have been identified in whole blood [18].

In this study, we performed miRNA microarrays in both fresh and 20-day storage RBCs washed and leuko-reduced to evaluate

\section{KARGER}

(C) 2018 S. Karger GmbH, Freiburg

Fax +497614520714 
potential dysregulated miRNAs in 20-day storage RBCs. Subsequently, miRNA target gene prediction was performed by the overlap of Miranda, Microcosm, and TargetScan databases with intersections $\geq 3$.

\section{Material and Methods}

\section{Ethics Approval and Consent to Participate}

All procedures performed in this study involving human participants were in accordance with the ethical standards of the Guangzhou First People's Hospital and the 1964 Helsinki declaration and its later amendments or comparable ethical standards. All participants in this study provided their written informed consent, data were kept anonymous, and this consent was approved by the Guangzhou First People's Hospital Ethics Committees consistent with the Article 15 of the Declaration of Helsinki (2008) on human subjects study.

\section{Blood Sample Collection and Groups}

Blood from 13 healthy adult male volunteers (aged 20-38 years, blood group $\mathrm{O}$ ) was collected in blood polyvinyl chloride plastic bags containing anticoagulant citrate dextrose solution A (ACD-A, Fresenius Kabi, Guangzhou, China) and stored in the anticoagulant citrate phosphate dextrose adenine solution (CPDA-1, Fresenius Kabi, Guangzhou, China). Each suspension was divided into 2 halves, one half was used for the analysis of fresh RBCs (fresh RBC group), and the other half was stored for 20 days at $4{ }^{\circ} \mathrm{C}$ as 20 -day storage $\mathrm{RBC}$ group. The choice of analyzing stored RBCs after 20 days is due to the fact that in Guangzhou First People's Hospital the stored blood is used for transfusion after more or less 3 weeks after collection, with an average storage time of 20 days, which actually represents half of the maximum storage period approved by US Food and Drug Administration [20].

\section{RBC Purification}

Suspended fresh RBCs were leuko-reduced prior to storage using a leukocyte depletion filter (Haemonetics Manufacturing Inc, Covina, CA, USA) from $4.98 \pm 1.79 \times 10^{9} / 1$ to $1.68 \pm 0.41 \times 10^{6} / 1$ to minimize potential leukocyte contamination. A total of $4.40 \times 10^{12} / 1 \mathrm{RBC}$ in each sample were tested. RBCs were additionally purified by washing them with $0.9 \% \mathrm{NaCl}$ and centrifuged three times at $1,400 \times g$ for 6 min to remove any platelet contamination.

\section{RNA Extraction}

Isolated RBCs were stored in RNAlater (Life Technologies, Carlsbad, CA, USA) at $-20{ }^{\circ} \mathrm{C}$ after their collection to avoid technical bias. Total RNA was extracted from both fresh RBCs and 20-day storage RBCs using TRIzol-LS (Invitrogen, Carlsbad, CA, USA), and both mRNA and miRNA were isolated using the miRNeasy mini kit (Qiagen, Shanghai, China) according to the manufacturers' instructions. RNA quality was evaluated using the spectrophotometer NanoDrop ND-1000 (Nanodrop Technologies, Wilmington, DE, USA).

\section{miRNA Microarray and Data Analysis}

miRNA expression profiling was performed by Kangchen Services Company (Shanghai, China) in both the fresh RBC group and the 20-day storage RBC group. Samples were labeled using miRCURY Hy3/Hy5 Power Labeling Kit (Exiqon, Vedbaek, Denmark) and hybridized on a miRCURY LNA Array version 18.0 (Exiqon). After washing, slides were scanned using an Axon GenePix 4000B microarray scanner (Axon Instruments, Foster City, CA, USA). Scanned images were imported into GenePix Pro 6.0 software (Axon) for grid alignment and data extraction. Replicated miRNAs were averaged, and miRNAs with an intensity $\geq 30$ in all samples were included in the calculation of a normalization factor. Expressed data were normalized using the median normalization. After normalization, significantly differentially expressed miRNAs were identified through volcano plot filtering. The threshold used to screen increased or decreased miRNAs was a fold change $\geq 2.0$ and a p value $\leq 0.05$. Finally, hierarchical clustering was performed using MEV software version 4.6
(TIGR) to show distinguishable miRNA expression profiling among samples. All data can be accessed at www.ncbi.nlm.nih.gov/geo/query/acc.cgi?acc $=$ GSE86905, the series record number is GSE86905. miRNAs selected for subsequent investigation were further filtered on the basis of expression levels and previously published data $[16,18]$.

\section{cDNA Synthesis of Mature miRNAs}

After RNA quantification, cDNA conversion for miRNA quantification was performed using Universal cDNA Synthesis Kit II (Exiqon). For each sample, cDNA was produced from $25 \mathrm{ng}$ of total RNA, according to a standard protocol. The mixture was incubated at $42{ }^{\circ} \mathrm{C}$ for $60 \mathrm{~min}, 95^{\circ} \mathrm{C}$ for $5 \mathrm{~min}$, cooled to $4{ }^{\circ} \mathrm{C}$, and stored at $-20^{\circ} \mathrm{C}$. Subsequently, cDNA was diluted $40 \times$ with RNasefree water prior to quantification by qRT-PCR.

\section{miRNAs qRT-PCR}

qRT-PCR was performed using a ViiA 7 real-time PCR machine (Applied Biosystems, Foster City, CA, USA), 96-well microtiter plates, and MicroAmP Fast Reaction Tubes. For miRNA quantification, an ExiLENT SYBR Green Master Mix Kit (Exiqon) was used in combination with miRCURY LNA PCR Primers (Exiqon). Primers were purchased from Takara (Takara Bio. Inc., Dalian, China), and their details are shown in supplemental table 1 (available at http://content.karger.com/ProdukteDB/produkte.asp?doi=489321).

Each reaction was performed in triplicate at a final volume of $10 \mu \mathrm{l}$ per well using the passive reference dye ROX II. The reaction conditions consisted of polymerase activation or denaturation and well-factor determination at $95{ }^{\circ} \mathrm{C}$ for $10 \mathrm{~min}$, followed by 40 amplification cycles at $95^{\circ} \mathrm{C}$ for $10 \mathrm{~s}$ and $60^{\circ} \mathrm{C}$ for 1 min, with a ramp rate of $1.6^{\circ} \mathrm{C} / \mathrm{s}$. The melting curve protocol began immediately after amplification and consisted of $65^{\circ} \mathrm{C}$ and $98^{\circ} \mathrm{C}$, with a $0.2^{\circ} \mathrm{C}$ increase at each step. CT values were determined using a manual baseline, and the mean CT was determined from the triplicate PCR results. The relative expression of each gene was calculated using comparative CT $\left(2^{-\triangle \Delta C T}\right)$ method. U6 snRNA was used as an internal control, and its expression stability was tested in RBCs.

\section{Target Genes Prediction}

miRNA target gene predictions were refined using Miranda (www.microrna.org/microrna/getGeneForm.do), Microcosm (www.ebi.ac.uk/enright-srv/ microcosm/cgi-bin/targets/v5/search.pl), and TargetScan (www.targetscan.org/ vert_61/) databases, which can efficiently provide information on miRNA sequences and target genes. The results obtained by different search programs were compared to find the common results. Thus, more intersections using more search programs correspond to more reliable results. Therefore, the final results were obtained by the overlap of the three databases with intersections $\geq$ $3, \geq 2, \geq 1$, based on the protocol and PCR panels from Qiagen (www.sabiosciences.com/ArrayList.php?pline $=$ PCRArray). Subsequently, enrichment analysis of the selected miRNAs and their predicted target genes was performed through KEGG pathways database (www.genome.jp/kegg/) to identify the miRNA-mRNA regulatory relationships. Finally, data were compiled and manually evaluated to identify individual miRNAs that target RBC apoptosis-, senescence- and membrane-related genes (mRNA).

\section{mRNA Expression Levels}

cDNA conversion for mRNA quantification was performed using PrimeScript RT Reagent Kit (Takara Bio. Inc). SYBR ${ }^{\circledR}$ Premix Ex Taq (Takara Bio. Inc) was used for qRT-PCR. Genes were selected according to the most significant results obtained by KEGG on miRNA-mRNA. Pairs of appropriate forward and reverse primers used (Takara Bio. Inc.) are shown in supplemental table 2 (available at http://content.karger.com/ProdukteDB/produkte.asp? doi $=489321)$

In brief, mRNA was first reverse-transcribed into cDNA using reverse primers in a thermal cycler at $37^{\circ} \mathrm{C}$ for $15 \mathrm{~min}$ and $85^{\circ} \mathrm{C}$ for $5 \mathrm{~s}$; samples were then cooled to $4{ }^{\circ} \mathrm{C}$ and stored at $-20^{\circ} \mathrm{C}$ until further use. Subsequently, cDNA (2 $\mu \mathrm{l})$ was amplified by PCR using the above primers. Each reaction was performed in triplicate at a final volume of $20 \mu \mathrm{l}$ per well using the passive reference dye ROX II; the fluorescence collection point was set to $60^{\circ} \mathrm{C}$. Reaction conditions consisted of polymerase activation/denaturation and well-factor de- 
termination at $95^{\circ} \mathrm{C}$ for $30 \mathrm{~s}$, followed by 40 amplification cycles at $95^{\circ} \mathrm{C}$ for 3 $\mathrm{s}, 60^{\circ} \mathrm{C}$ for $30 \mathrm{~s}$ and $95^{\circ} \mathrm{C}$ for $15 \mathrm{~s}$. The melting curve protocol began immediately after amplification and consisted of heating at $95^{\circ} \mathrm{C}$ for $15 \mathrm{~s}$ and $60{ }^{\circ} \mathrm{C}$ for $60 \mathrm{~s}$. Relative expression of each gene was calculated according to the comparative $2^{-\Delta \Delta C T}$ method using GAPDH as internal reference, where $\Delta \mathrm{CT}=\mathrm{CT}$ (target gene) - CT $(G A P D H)$ and $\triangle \triangle \mathrm{CT}=\triangle \mathrm{CT}$ (sample) $-\triangle \mathrm{CT}$ (control). Data are presented as fold change of each mRNA.

\section{Statistical Analysis}

Data are shown as mean \pm SD. Statistical analysis was performed using SPSS software version 13.0 (IBM, Armonk, NY, USA). Univariate and paired-sample Student's t-test was used to assess statistical significance between fresh RBC group and 20-day storage RBC group. Residual error was used to test the normality. Post-hoc multiple comparisons test (LSD t test) was performed, where appropriate. Statistical significance was set at $\mathrm{p}<0.05$.

\section{Results}

\section{miRNAs Expression Profiles in 20-Day Storage RBC Group}

To define the differential expression profile of miRNA in RBCs during storage, set of miRNAs expressed in the 20-day storage $\mathrm{RBC}$ group were compared to those of fresh RBC group. Supplemental figure 1 (available at http://content.karger.com/ProdukteDB/ produkte.asp?doi=489321) shows the heat map and hierarchical clustering ( $\mathrm{n}=3$, representative of the results for all the 13 donors) between 20-day storage RBC group and fresh RBC group. The results revealed that 211 miRNAs were dysregulated in a total of 3,100 miRNAs, divided into 109 increased and 102 decreased miRNAs. Table 1 shows the 10 miRNAs with the highest/lowest level in the 20-day storage RBC group.

\section{Target Genes Prediction}

The final results obtained by the overlap of Miranda, Microcosm and TargetScan databases used for miRNA target gene predictions with intersections $\geq 3, \geq 2, \geq 1$ are shown in table 2 . With an intersection $\geq 3,8$ miRNAs and 352 mRNAs were found to be involved in miRNA-mRNA networks while with an intersection $\geq$ 2, 10 miRNAs and 5,104 mRNAs were found (table 2). In addition, enrichment analysis showed that these miRNAs were involved in 50 or 75 signaling pathways, including apoptosis, senescence and $\mathrm{RBC}$ differentiation pathways (data not shown).

\section{Validation of Selected miRNAs by qRT-PCR}

The eight predicted miRNAs with an intersection $\geq 3$ were evaluated by qRT-PCR. miR-31-5p, miR-196a-5p, miR-203a, miR-654-3p and miR-769-3p were increased, while miR-96-5P, miR-150-5P and miR-197-3p were decreased (table 3).

\section{Target mRNAs Validated by $q R T-P C R$}

Target gene mRNAs were evaluated according to miRNA changes in our results related to the intersection $\geq 3$ shown in

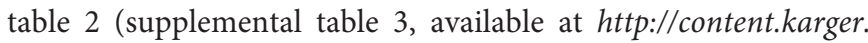
com/ProdukteDB/produkte.asp?doi=489321).

Among the many target mRNAs listed in supplemental table 3 (available at http://content.karger.com/ProdukteDB/produkte.asp?

Table 1. miRNAs top- 10 list in 20 -day storage RBCs group, obtained by microarray

\begin{tabular}{lll}
\hline miRNA & \multicolumn{2}{l}{$\begin{array}{l}\text { 20-day storage RBCs group vs fresh RBCs } \\
\text { group }\end{array}$} \\
\cline { 2 - 3 } & fold change & p value \\
\hline Increased & & \\
hsa-miR-203a & $16.15 \pm 7.25$ & 0.022 \\
hsa-miR-654-3p & $14.30 \pm 5.63$ & 0.003 \\
hsa-miR-31-5p & $12.68 \pm 6.26$ & 0.040 \\
hsa-miR-769-3p & $11.01 \pm 1.84$ & 0.006 \\
hsa-let-7d-3p & $9.70 \pm 4.30$ & 0.001 \\
hsa-miR-4740-5p & $9.26 \pm 12.3$ & 0.041 \\
hsv1-miR-H5-5p & $7.22 \pm 3.38$ & 0.013 \\
hsa-miR-642b-3p & $6.52 \pm 1.45$ & 0.022 \\
ebv-miR-BART6-3p & $6.26 \pm 3.00$ & 0.019 \\
hsa-miR-506-5p & $5.30 \pm 2.90$ & 0.043 \\
\hline Decreased & & \\
hsa-miR-5692c & & \\
hsa-miR-145-3p & $0.02 \pm 0.05$ & 0.006 \\
hsa-miR-299-3p & $0.02 \pm 0.02$ & 0.032 \\
hsa-miR-4682 & $0.03 \pm 0.02$ & 0.001 \\
hsa-miR-3129-5p & $0.03 \pm 0.04$ & 0.003 \\
hsa-miR-100-5p & $0.04 \pm 0.02$ & 0.008 \\
hsa-miR-944 & $0.04 \pm 0.01$ & 0.011 \\
hsa-miR-3591-5p & $0.04 \pm 0.02$ & 0.003 \\
hsa-miR-676-3p & $0.05 \pm 0.11$ & 0.012 \\
hsa-miR-4777-5p & $0.07 \pm 0.05$ & 0.014 \\
\hline & $0.07 \pm 0.03$ & 0.012 \\
\hline
\end{tabular}

Table 2. Target gene prediction using specific search programs

\begin{tabular}{lccccccc}
\hline miRNA & Miranda & $\begin{array}{l}\text { Microcosm } \\
\text { (mirbase) }\end{array}$ & Targetscan & Summary & $\begin{array}{l}\text { Intersection } \\
(\geq 3)\end{array}$ & $\begin{array}{l}\text { Intersection } \\
(\geq 2)\end{array}$ & $\begin{array}{l}\text { Intersection } \\
(\geq 1)\end{array}$ \\
\hline miR-31-5p & 3,698 & 955 & 368 & 3,259 & 31 & 497 & 2,762 \\
miR-196a-5p & 2,783 & 1,149 & 807 & 2,827 & 44 & 405 & 2,422 \\
miR-203a & 8,936 & 902 & 868 & 5,849 & 88 & 987 & 4,862 \\
miR-654-3p & 3,854 & 947 & 164 & 3,381 & 8 & 367 & 3,014 \\
miR-769-3p & 2,534 & 1,276 & 103 & 2,658 & 11 & 246 & 2,412 \\
miR-96-5P & 3,785 & 1,113 & 1,048 & 3,700 & 112 & 826 & 2,874 \\
miR-150-5P & 3,880 & 835 & 275 & 3,261 & 44 & 401 & 2,860 \\
miR-197-3p & 3,115 & 916 & 0 & 2,893 & 14 & 314 & 2,579 \\
miR-3129-5p & 3,671 & 0 & 401 & 2,730 & 0 & 309 & 2,421 \\
miR-145-3p & 3,627 & 887 & 0 & 3,040 & 0 & 207 & 2,833 \\
miR-5692c & 0 & 0 & 0 & 0 & 0 & 0 & 0 \\
\hline
\end{tabular}


Table 3. miRNAs expression by qRT-PCR

\begin{tabular}{lll}
\hline miRNA & \multicolumn{2}{c}{ 20-day storage RBCs group vs. fresh RBCs group } \\
\cline { 2 - 3 } & fold change & $\mathrm{p}$ value \\
\hline Increased & & \\
miR-31-5p & $1.86 \pm 0.64$ & 0.040 \\
miR-196a-5p & $3.44 \pm 1.89$ & 0.044 \\
miR-203a & $2.72 \pm 1.06$ & 0.022 \\
miR-654-3p & $2.97 \pm 0.65$ & 0.003 \\
miR-769-3p & $3.94 \pm 1.23$ & 0.006 \\
Decreased & & \\
miR-96-5p & & \\
miR-150-5p & $0.19 \pm 0.16$ & 0.0001 \\
miR-197-3p & $0.35 \pm 0.14$ & 0.013 \\
\hline
\end{tabular}

$d o i=489321)$, 9 were chosen for further analysis based on the intersection $\geq 2$ by KEGG and associated with apoptosis and senescence (supplemental table 4, available at http://content.karger.com/ ProdukteDB/produkte.asp?doi=489321).

Our results showed that BTG Family Member 2 (BTG2) was increased in the 20-day storage RBC group, while RapamycinInsensitive Companion of mTOR (RICTOR), serine/threonine kinase (ATM), caspase 10 (CASP10), caspase 8 (CASP8), interleukin 3 (IL3), Baculoviral IAP Repeat-Containing 6 (BIRC6), MitogenActivated Protein Kinase 14 (MAP3K14) and Erythrocyte Membrane Protein Band 4.1-like 4B (EPB41L4B) were decreased in the 20-day storage RBCs group (supplemental table 4, available at http://content.karger.com/ProdukteDB/produkte.asp?doi=489321). These mRNAs belong to 3 groups related to apoptosis, senescence, and RBC membrane, as follows: i) BIRC6, RICTOR, CASP8, CASP10, BTG2, IL3, ATM, and MAP3K1 are apoptotic-related genes in RBCs, and CASP8, CASP10, IL3, ATM, and MAP3K14 are involved in the apoptotic signaling pathways in KEGG; ii) $A T M$ is a RBC senescence-related gene; iii) EPB $41 L 4 B$ is an RBC membrane-related gene. However, in our qRT-PCR confirmation, only RICTOR, CASP8, and CASP10 were found to be significantly changed, despite all these 9 genes we considered were significantly dysregulated according to KEGG.

\section{Discussion and Conclusion}

RBCs may be stored up to 35 days before transfusion according to Chinese standards and up to 42 days according to US and EU standards [20-22]. Although there are evidences reporting the potential harm of transfusing stored RBCs [1-11], other studies on randomized clinical trials reported no difference in mortality of patients who received fresher versus older RBCs [23-26]. Most published clinical studies are non-randomized observational studies with methodologic limitations. Therefore, according to these evidences, it is still difficult to evaluate the positive or negative clinical impact of using stored RBCs on patients [22, 27, 28]. Actually, stored RBCs undergo slow deleterious changes over time during storage, decreasing their viability at $24 \mathrm{~h}$ post-transfusion to $70 \%$ in the 35 days stored RBCs [29], although these stored RBCs still meet the storage level accepted by several countries [20-22]. Despite more attention is now being paid to the storage damage found in banked RBCs, further studies are needed to increase our knowledge on RBC storage modifications to evaluate their potential consequences. miRNAs are endogenous non-coding small single RNAs molecules that play important roles in several life processes including cell apoptosis, differentiation, and proliferation. Therefore, we believe that miRNA changes in stored RBCs may represent potential biomarkers of storage lesions.

miRNAs present in mature RBCs are more abundant compared to the amount present in other blood cells, including leukocytes and platelets $[16,18,19]$. Thus, although the presence of other blood cells should not influence the results associated to miRNA, we performed our study on leuko-reduced RBCs in accordance to the rule followed by Guangzhou First People's Hospital of using leuko-reduced RBCs for transfusion and the consequent need of establishing storage lesions in these leuko-reduced samples. Kannan and Atreya [18] reported that miR-96, miR-150, and miR-197 increased in RBCs during 20 days of storage, which is opposite to the decreased levels we found. The main reason might be associated to the difference in samples used, since we used leuko-reduced RBCs, while Kannan and Atreya [18] used non-leuko-reduced whole blood. Although on the basis of our results we could not explain how exactly this difference in samples used could result in different results obtained, the fact that Kannan and Atreya [18] used blood samples differing from those we used could not be ignored and should be considered when comparing our results to those of Kannan and Atreya [18]. However, both our results and those of Kannan and Atreya [18] showed dysregulation of miR-96, miR-150, and miR-197, even though with opposite trend; thus we provided an additional evidence that these three miRNA are sensible to storage.

Our results revealed that 211 miRNAs were dysregulated in the 20 -day storage RBC group compared to the fresh RBC group, and through the intersection $\geq 3$ we highlighted that 8 of them were significantly dysregulated. The role of these dysregulated miRNAs in RBCs is not yet known for all of them. miRNA-150 is one of the most extensively studied miRNAs, revealing multiple roles in both blood cells and other cells types. In addition, it is also a tumor suppressor, since its decrease induces activation of specific pathways leading to immortalization of cancer cells and malignant lymphoma [30]. Importantly, Zhang et al. [31] demonstrated that miRNA-150 secreted by human blood cells can increase HMEC-1 cell migration after being delivered into these cells, suggesting that miRNA-150, and miRNAs in general, can be secreted by cells and can be delivered into other cells,consequently influencing the recipient cell function. Thus, our result on miRNA-150 in stored RBCs could not be significantly related to RBC health status per se.

miRNA-96 is known for its abundance in adult blood reticulocytes, where it decreases $\gamma$-globin expression typical of fetal hemoglobin $(\alpha 2 \gamma 2)$ allowing for the predominance of adult hemoglobin $(\alpha 2 \beta 2)$ when reticulocytes mature into erythrocytes [32, 33]. As a 
consequence of that, miRNA-96 silencing induces an increase in $\gamma$-globin $[32,33]$. In addition, overexpression of miRNA-96-5p inhibits autophagy and apoptosis in human breast cancer cells [34]. Thus, although our results are referred to RBCs, this evidence could indicate that miRNA-96 decrease might be a sign of ongoing $\mathrm{RBC}$ autophagy and apoptosis.

Both miRNA-197 and miRNA-96 are associated with increased systolic blood pressure and mean arterial pressure [35], suggesting that the decrease of both miRNA as shown in our study could result in reduced blood pressure. In addition, increased miR-196a in stem cells is associated with increased senescence [36]. Although not directly referred to RBCs, these evidence cannot be ignored, since it reveals an involvement of this miRNA in senescence pathways.

Little is known about the role of miR-31-5p, miR-203a, miR654-3p and miR-769-3p in RBCs or in blood in general. However, evidence related to their role in other cell types could be an indication to understand their potential effect when increasing in RBCs. miR-31-5p is increased in aging endothelial cells isolated from umbilical cords, and it is considered as a human liver aging marker since it increases in livers of old age donors [37, 38]. A recent study shows that miR-203a induces apoptosis in human scar fibroblasts [39]. miR-654-3p overexpression induced in human prostate cancer cells and tumor thyroid cells increases the percentage of apoptotic cells, but it also increases apoptosis in normal thyroid cells $[40,41]$. Overexpression of miR-769-3p in breast cancer cells increases apoptosis; thus, it could be also critical in RBC survival [42]. These reports shed light on the involvement of those miRNAs in apoptosis and senescence signaling pathways.

Only little is known on the half-life of miRNA in RBCs and other cell types. Van Rooij et al. [43] reported a miRNA half-life of up to 12 days in cardiac cells; Both Chen et al. [44] and Wang et al. [45] reported longer half-life and slower decay kinetics of specific miRNAs in erythrocytes, although they do not mention the length of their half-life ; Heneghan et al. [46] reported that the half-life of tumor-associated miRNAs in the blood is undefined. With respect to these results, miRNAs could accumulate during maturation from reticulocytes to mature RBCs, and this accumulation could also persist for a while during storage and might be perceived as an increase. However, nucleic acids and proteins may undergo degradation due to the physiological stress during RBC storage, depending on their individual half-life [18]. Furthermore, Said et al. [47] identified RBC-derived miRNAs packaged into nano- or microparticles that are shed into the supernatant from senescent and dam- aged RBCs. Thus, this might also contribute to decreased miRNA levels in stored RBCs. On the other hand, transfusion of miRNAcontaining particles could potentially have biological implications. These events could also explain the increase we observed in some miRNAs and the decrease in some others.

Target gene mRNAs were evaluated according to miRNAs changes, and, among the many target mRNAs, the eight most significant results obtained by KEGG were selected according to their involvement in apoptosis, cellular senescence, and RBC membrane pathways. Although only RICTOR, CASP10, and CASP8 expressions were significantly decreased, we could show for the first time that their decrease in stored RBCs is actually associated with apoptosis. Indeed, CASP8 and CASP10 are pro-apoptotic. RICTOR on the other hand is a key regulator of the mTOR signaling pathway, and it can induce eNOS activity and release NO level by eNOS phosphorylation; its expression inhibits apoptosis of endothelial cells induced by TNF $[26,48]$. On the basis of these gene functions, our results suggest that miRNA dysregulation might influence miRNA-mRNA interaction, confirming once more the role of miRNAs in RBC storage lesion and suggesting that miRNAs in $\mathrm{RBCs}$ represent potential apoptotic markers.

In conclusion, our work highlighted the dysregulation of miRNAs which have not been reported before in stored RBCs, suggesting that miRNAs might play a role in storage lesion. Thus, those dysregulated miRNAs identified in the 20-day storage RBC group might be considered as storage lesion biomarkers and might be useful to predict the quality of stored RBCs.

\section{Acknowledgments}

This manuscript underwent English language editing and proofreading offered by Mogo Internet Technology Co., LTD.

\section{Funding}

This work was supported by the National Natural Science Foundation of China (\#81070385), and Guangzhou Planned Project of Science and Technology (\#201300000100).

\section{Disclosure Statement}

The authors declare no conflict of interests.

\section{References}

$>_{1}$ Bennett-Guerrero E, Veldman TH, Doctor A, Telen MJ, Ortel TL, Reid TS, Mulherin MA, Zhu H, Buck RD, Califf RM, McMahon TJ: Evolution of adverse changes in stored RBCs. Proc Natl Acad Sci U S A 2007;104:17063-17068.

2 Glynn SA: The red blood cell storage lesion: a method to the madness. Transfusion 2010;50:1164-1169.
3 Henkelman S, Dijkstra-Tiekstra MJ, de Wildt-Eggen J, Graaff R, Rakhorst G, van Oeveren W: Is red blood cell rheology preserved during routine blood bank storage? Transfusion 2010;50:941-948.

4 Reynolds JD, Ahearn GS, Angelo M, Zhang J, Cobb F, Stamler JS: S-nitrosohemoglobin deficiency: a mechanism for loss of physiological activity in banked blood. Proc Natl Acad Sci U S A 2007;104:17058-17062.
5 Xu Z, Zheng Y, Wang X, Shehata N, Wang C, Sun Y: Stiffness increase of red blood cells during storage. Microsystems Nanoengineering 2018;4:17103-17108.

6 Chien S: Red cell deformability and its relevance to blood flow. Annu Rev Physiol 1987;49:177-192.

7 Parthasarathi K, Lipowsky HH: Capillary recruitment in response to tissue hypoxia and its dependence on red blood cell deformability. Am J Physiol 1999;277: H2145-2157. 
- 8 Rao SV, Jollis JG, Harrington RA, Granger CB, Newby LK, Armstrong PW, Moliterno DJ, Lindblad L, Pieper K, Topol EJ, Stamler JS, Califf RM: Relationship of blood transfusion and clinical outcomes in patients with acute coronary syndromes. JAMA 2004;292: $1555-1562$.

9 Tinmouth A, Fergusson D, Yee IC, Hebert PC: Clinical consequences of red cell storage in the critically ill. Transfusion 2006;46:2014-2027.

10 Xie X, Yao H, Yang X, Wei Y: Effects of SNP on hemorheology and nitric oxide levels in stored erythrocyte. Chin J Blood Transfus 2014;27:136-139.

11 Xing Y, Wu Q, Xie X, Cui Y, Yuan Z, Yang X, Wei Y Alteration of NO and ATP level in stored RBC incubated with SNP at $37^{\circ} \mathrm{C}$. Chin J Blood Transfus 2016; 29:791-794.

12 Bartel DP: MicroRNAs: genomics, biogenesis, mechanism, and function. Cell 2004;116:281-297.

13 Chen X, Ba Y, Ma L, Cai X, Yin Y, Wang K, Guo J, Zhang Y, Chen J, Guo X, Li Q, Li X, Wang W, Wang J, Jiang X, Xiang Y, Xu C, Zheng P, Zhang J, Li R, Zhang H, Shang X, Gong T, Ning G, Zen K, Zhang CY: Characterization of microRNAs in serum: a novel class of biomarkers for diagnosis of cancer and other diseases. Cell Res 2008;18:997-1006.

14 Lim LP, Lau NC, Garrett-Engele P, Grimson A, Schelter JM, Castle J, Bartel DP, Linsley PS, Johnson JM: Microarray analysis shows that some microRNAs downregulate large numbers of target mRNAs. Nature 2005;433:769-773.

15 Goh SH, Lee YT, Bouffard GG, Miller JL: Hembase: browser and genome portal for hematology and erythroid biology. Nucleic Acids Res 2004;32:D572-574.

16 Sangokoya C, LaMonte G, Chi JT: Isolation and characterization of microRNAs of human mature erythrocytes. Methods Mol Biol 2010;667:193-203.

17 Teruel-Montoya R, Kong X, Abraham S, Ma L, Kunapuli SP, Holinstat M, Shaw CA, McKenzie SE, Edelstein LC, Bray PF: MicroRNA expression differences in human hematopoietic cell lineages enable regulated transgene expression. PLoS One 2014;9:e102259.

18 Kannan M, Atreya C: Differential profiling of human red blood cells during storage for 52 selected microRNAs. Transfusion 2010;50:1581-1588.

19 Ryan P, Atreya C: Blood cell microRNAs: what are they and what future do they hold? Transfus Med Rev 2011;25:247-251.

20 Dumont LJ, AuBuchon JP: Evaluation of proposed FDA criteria for the evaluation of radiolabeled red cell recovery trials. Transfusion 2008;48:1053-1060.

21 Chen Y, Zhang J, Gu S, Yin D, An Q, An N, Weng L, Yi J, Xu J, Yin W, Hu X: Mesenchymal stromal cells can be applied to red blood cells storage as a kind of cellular additive. Biosci Rep 2017;37:doi: 10.1042/ BSR20170676.

22 Roback JD: Perspectives on the impact of storage duration on blood quality and transfusion outcomes. Vox Sang 2016;111:357-364.

-23 Alexander PE, Barty R, Fei Y, Vandvik PO, Pai M, Siemieniuk RA, Heddle NM, Blumberg N, McLeod SL, Liu J, Eikelboom JW, Guyatt GH: Transfusion of fresher vs older red blood cells in hospitalized patients: a systematic review and meta-analysis. Blood 2016;127: 400-410.
24 Chai-Adisaksopha C, Alexander PE, Guyatt G, Crowther MA, Heddle NM, Devereaux PJ, Ellis M, Roxby D, Sessler DI, Eikelboom JW: Mortality outcomes in patients transfused with fresher versus older red blood cells: a meta-analysis. Vox Sang 2017;112: 268-278.

25 Cooper DJ, McQuilten ZK, Nichol A, Ady B, Aubron C, Bailey M, Bellomo R, Gantner D, Irving DO, Kaukonen KM, McArthur C, Murray L, Pettila V, French C: Age of Red Cells for Transfusion and Outcomes in Critically Ill Adults. N Engl J Med 2017;377:18581867.

26 Rygard SL, Jonsson AB, Madsen MB, Perner A, Holst LB, Johansson PI, Wetterslev J: Effects of shorter versus longer storage time of transfused red blood cells in adult ICU patients: a systematic review with metaanalysis and Trial Sequential Analysis. Intensive Care Med 2018;44:204-217.

27 Pereira A: Will clinical studies elucidate the connection between the length of storage of transfused red blood cells and clinical outcomes? An analysis based on the simulation of randomized controlled trials. Transfusion 2013;53:34-40.

28 Triulzi DJ, Yazer MH: Clinical studies of the effect of blood storage on patient outcomes. Transfus Apher Sci 201;43:95-106.

29 Fung MK, Grossman BJ, Hillyer CD, Westhofl CW: AABB Technical Manual. 18th ed. Bethesda, AABB, 2014.

30 Watanabe A, Tagawa H, Yamashita J, Teshima K, Nara M, Iwamoto K, Kume M, Kameoka Y, Takahashi N, Nakagawa T, Shimizu N, Sawada K: The role of microRNA-150 as a tumor suppressor in malignant lymphoma. Leukemia 2011;25:1324-1334.

31 Zhang Y, Liu D, Chen X, Li J, Li L, Bian Z, Sun F, Lu J, Yin Y, Cai X, Sun Q, Wang K, Ba Y, Wang Q, Wang D, Yang J, Liu P, Xu T, Yan Q, Zhang J, Zen K, Zhang CY: Secreted monocytic miR-150 enhances targeted endothelial cell migration. Mol Cell 2010;39:133-144.

32 Azzouzi I, Moest H, Winkler J, Fauchere JC, Gerber AP, Wollscheid B, Stoffel M, Schmugge M, Speer O: MicroRNA-96 directly inhibits gamma-globin expression in human erythropoiesis. PLoS One 2011; 6:e22838.

33 Listowski MA, Heger E, Boguslawska DM, Machnicka B, Kuliczkowski K, Leluk J, Sikorski AF: microRNAs: fine tuning of erythropoiesis. Cell Mol Biol Lett 2013; 18:34-46.

34 Shi Y, Zhao Y, Shao N, Ye R, Lin Y, Zhang N, Li W, Zhang Y, Wang S: Overexpression of microRNA96-5p inhibits autophagy and apoptosis and enhances the proliferation, migration and invasiveness of human breast cancer cells. Oncol Lett 2017;13:4402-4412.

35 Zhang Z, Joyce BT, Kresovich JK, Zheng Y, Zhong J, Patel R, Zhang W, Liu L, Dou C, McCracken JP, Diaz A, Motta V, Sanchez-Guerra M, Bian S, Bertazzi PA, Schwartz J, Baccarelli AA, Wang S, Hou L: Blood pressure and expression of microRNAs in whole blood. PLoS One 2017;12:e0173550.
36 Candini O, Spano C, Murgia A, Grisendi G, Veronesi E, Piccinno MS, Ferracin M, Negrini M, Giacobbi F, Bambi F, Horwitz EM, Conte P, Paolucci P, Dominici M: Mesenchymal progenitors aging highlights a miR196 switch targeting HOXB7 as master regulator of proliferation and osteogenesis. Stem Cells 2015;33: 939-950.

37 Capri M, Olivieri F, Lanzarini C, Remondini D, Borelli V, Lazzarini R, Graciotti L, Albertini MC, Bellavista E, Santoro A, Biondi F, Tagliafico E, Tenedini E, Morsiani C, Pizza G, Vasuri F, D’Errico A, Dazzi A, Pellegrini S, Magenta A, D’Agostino M, Capogrossi MC, Cescon M, Rippo MR, Procopio AD, Franceschi C, Grazi GL: Identification of miR-31-5p, miR-141-3p, miR-200c-3p, and GLT1 as human liver aging markers sensitive to donor-recipient age-mismatch in transplants. Aging Cell 2017;16:262-272.

38 Kuosmanen SM, Kansanen E, Sihvola V, Levonen AL: MicroRNA Profiling Reveals Distinct Profiles for Tissue-Derived and Cultured Endothelial Cells. Sci Rep 2017;7:10943.

39 Han W, Daojiang Y, Zhao T: The role of miR-203a in hypertrophic scars and its mechanism. Int J Clin Exp Pathol 2017;10:5366-5372.

40 Formosa A, Markert EK, Lena AM, Italiano D, FinazziAgro E, Levine AJ, Bernardini S, Garabadgiu AV, Melino G, Candi E: MicroRNAs, miR-154, miR299-5p, miR-376a, miR-376c, miR-377, miR-381, miR487b, miR-485-3p, miR-495 and miR-654-3p, mapped to the $14 \mathrm{q} 32.31$ locus, regulate proliferation, apoptosis, migration and invasion in metastatic prostate cancer cells. Oncogene 2014;33:5173-5182.

41 Geraldo MV, Nakaya HI, Kimura ET: Down-regulation of 14q32-encoded miRNAs and tumor suppressor role for miR-654-3p in papillary thyroid cancer. Oncotarget 2017;8:9597-9607.

42 Luo EC, Chang YC, Sher YP, Huang WY, Chuang LL, Chiu YC, Tsai MH, Chuang EY, Lai LC: MicroRNA769-3p down-regulates NDRG1 and enhances apoptosis in MCF-7 cells during reoxygenation. Sci Rep 2014; 4:5908

43 van Rooij E, Sutherland LB, Qi X, Richardson JA, Hill $\mathrm{J}$, Olson EN: Control of stress-dependent cardiac growth and gene expression by a microRNA. Science 2007;316:575-579.

44 Chen SY, Wang Y, Telen MJ, Chi JT: The genomic analysis of erythrocyte microRNA expression in sickle cell diseases. PLoS One 2008;3:e2360.

45 Wang B, Love TM, Call ME, Doench JG, Novina CD: Recapitulation of short RNA-directed translational gene silencing in vitro. Mol Cell 2006;22:553-560.

46 Heneghan HM, Miller N, Lowery AJ, Sweeney KJ, Newell J, Kerin MJ: Circulating microRNAs as novel minimally invasive biomarkers for breast cancer. Ann Surg 2010;251:499-505.

47 Said AS, Rogers SC, Doctor A: Physiologic impact of circulating RBC Microparticles upon blood-vascular interactions. Front Physiol 2017;8:1120.

48 Dormond O, Madsen JC, Briscoe DM: The effects of mTOR-Akt interactions on anti-apoptotic signaling in vascular endothelial cells. J Biol Chem 2007;282: 23679-23686. 